\title{
O PARADIGMA DA INTENSA UTILIZAÇÃO DE AGROTÓXICOS NO BRASIL SOB O CONTEXTO DA MUNDIALIZAÇÃO DA AGRICULTURA
}

\author{
Rafaela Monique de Oliveira Sampaio* \\ João da Cruz Gonçalves Neto**
}

Resumo: Durante a Ditadura Militar no Brasil, a agricultura deixou de ser subordinada à indústria, passando a ser a própria indústria a céu aberto. Essa junção foi tão intensa que a agricultura moderna já nasceu dependente da indústria de agrotóxicos, que se expandiu rapidamente, e sob o domínio de poucas empresas, pelo mundo todo. $\mathrm{O}$ intuito desse texto é evidenciar o contexto da utilização de agrotóxicos no Brasil sob os efeitos da mundialização da agricultura. A pesquisa será qualitativa e se baseará em artigos científicos e textos doutrinários.

Palavras-chave: Direito Agrário. Agrotóxicos. Ditadura militar. Mundialização da agricultura.

\section{THE PARADIGM OF THE INTENSE USE OF AGROCHEMICALS IN BRAZIL UN- DER THE CONTEXT OF THE GLOBALIZATION OF AGRICULTURE}

\begin{abstract}
During the military dictatorship in Brazil, agriculture ceased to be subordinated to industry, becoming the industry itself in the open. This juncture was so intense that modern agriculture was born dependent on the agrochemical industry, which expanded rapidly, and under the control of few companies, all over the world. The purpose of this text is to highlight the context of the use of agrochemicals in Brazil under the effects of the globalization of agriculture. The research will be qualitative and will be based on scientific articles and doctrinal texts.
\end{abstract}

Keywords: Agrarian Law. Pesticides. Military dictatorship. Globalization of agriculture

\footnotetext{
* Mestranda em Direito agrário; Servidora efetiva do Ministério Público do Estado de Goiás. Bacharel em Direito e especialista em direito público e docência superior (Direito Constitucional, Administrativo, Tributário e Previdenciário) com aprovação no exame de ordem e atuação profissional, praticamente durante todo o histórico profissional, no serviço público. E-mail: rafaelamonique @ gmail.com.

${ }_{* *}^{*}$ Graduação em Filosofia pela Universidade Federal de Goiás (1989), graduação em Direito pela Universidade Federal de Goiás (1998), mestrado em Filosofia pela Universidade Federal de Goiás (2000), doutorado em Filosofia pela Pontifícia Universidade Católica do Rio Grande do Sul (2006) e pós-doutorado em direito pela Universidade Federal de Santa Catarina. Atualmente é professor associado na Faculdade de Direito da Universidade Federal de Goiás e coordenador do Núcleo de Estudos e Pesquisas em Direitos Humanos da UFG. E-mail: dellacroce@dellacroce.pro.br.
} 


\section{INTRODUÇÃO}

O termo mundialização do capital foi cunhado por François Chesnais em seu livro La mondialisation du capital ${ }^{1}$. Segundo ele, no final do século XX houve um novo pacto de poder envolvendo a burguesia do mundo inteiro, no intuito de atender os interesses comuns dos burgueses locais. De modo que, a aliança traduziu a cooperação mútua para a retirada de barreiras nacionais que impediam a consecução dos interesses econômicos comuns dos acordantes. Essa transação "amalgamou" o capital de diferentes países em uma escala mundial. (OLIVEIRA, 2015, p.235)

Estava instalada a denominada globalização ${ }^{2}$ e palavras como soberania nacional, protecionismo econômico, intervenção do Estado na Economia, regulação de mercado, fortalecimento do Estado, passaram a ser censuradas e aliadas à noção de atraso. Agora, os termos adequados eram e ainda são: livre comércio mundial, autorregulação de mercado, privatização de empresas estatais, terceirização de serviços públicos, abertura da economia nacional para as multinacionais e tantos outros vocábulos midiáticos oriundos do neoliberalismo.

A agricultura capitalista, inevitavelmente, foi absorvida por essa transformação, passando a se estruturar em três pilares: a produção de commodities, as bolsas de mercadorias e de futuro e a formação de empresas monopolistas mundiais. A atuação da agricultura neoliberal ocorre através do controle da propriedade privada da terra, do processo produtivo e industrial do campo (territorialização dos monopólios) e por meio das empresas que processam e vendem alimentos sem produzir nada no campo, subordinando os fazendeiros e camponeses à sua lógica de mercado (monopolização dos territórios) (OLIVEIRA, 2012; OLIVEIRA, 2015)

O histórico da instalação do paradigma da intensa utilização de venenos agrícolas no Brasil e consequentemente da implantação do monopólio das indústrias de agrotóxicos no cenário nacional demonstra as consequências da transformação capitalista da agricultura. Por isso, o intuito desse texto é trazer um olhar específico sobre a indústria de agrotóxicos no Brasil, sob o contexto da mundialização da agricultura.

\footnotetext{
${ }^{1}$ Livro: A Mundialização da Agricultura Brasileira. Iãnde Editorial. São Paulo, 2016.

2. Em profundidade, aponta o autor que: "O uso intenso dos termos global e globalização, vieram da mídia econômica norte-americana para a ciência e não ao contrário. Ou seja, a mídia passava a pautar a ciência e não a ciência pautar a mídia" (OLIVEIRA, 2012, p. 2)
} 


\section{O PARADIGMA DA INTENSA UTILIZAÇÃO DE AGROTÓXICOS NO BRASIL SOB O CONTEXTO DA MUNDIALIZAÇÃO DA AGRICULTURA}

De início, faremos um breve retrospecto histórico sobre o momento de instalação do paradigma que ainda vigora no Brasil, analisando a postura do Poder Público e suas responsabilidades na implantação do sistema de intensa utilização de venenos agrícolas no solo nacional.

Na sequência, demonstraremos que o mercado de agrotóxicos foi (e ainda é) fortemente subsidiado pelo Estado, que usou vários instrumentos de políticas públicas para beneficiar e expandir o setor.

Veremos que todos os incentivos feitos pelo Poder Público para a entrada de produtos altamente tóxicos destinados a agricultura nacional foram feitos sob a égide de um Decreto regulamentador que datava de 1.934, com normas defasadas e flexíveis, combinadas com a falta de controle, capacitação e monitoramento dos resíduos desses produtos.

Ações como os incentivos fiscais, crédito rural, norma flexível e defasada, dentre outros aspectos, resultaram em mais de $3.000 \%$ de aumento do uso de veneno agrícolas durante o período militar.

A modificação do modo de produção, por consequência ou em razão da mundialização do capital, e da agricultura tem na indústria de agrotóxicos um de seus principais expoentes, cuja característica monopolista será destacada nesse texto. A pesquisa será qualitativa e se apoiará em artigos científicos e textos doutrinários.

\section{O PARADIGMA DA INTENSA UTILIZAÇÃO DE AGROTÓXICOS NO BRASIL: COMO TUDO COMEÇOU ${ }^{3}$}

As décadas de 60, 70 e 80 do século XX foram marcadas por profundas mudanças econômicas, sociais e agrárias no Brasil e no mundo. Foi exatamente nesse período que houve a "grande transformação" (ou tentativa) da terra em mercadoria". De subordinada à indústria, a agricultura passou a ser a própria indústria a céu aberto. À osmose entre o complexo

\footnotetext{
${ }^{3}$. A indicação das responsabilidades do Estado durante o regime militar quanto à instalação do paradigma do uso intenso de agrotóxicos no país não isenta a responsabilidade dos governos subsequentes, apenas temos o intuito de demonstrar que o sistema que ainda vigora foi criado e formado durante o governo dos militares.

${ }^{4}$. Importante destacar que vários autores, como por exemplo o Professor Carlos Frederico Marés (a função social da terra), entendem ser impossível transformar a terra em mercadoria por conta de suas especificidades. Nos incluímos nesse posicionamento, mas a postura econômica ainda predomina e diverge desse entendimento.

5. Expressão de Karl Polanyi em "a grande transformação: as origens de nossa época. Rio de Janeiro, Campus, $1980 "$
} 
industrial e a agricultura deu-se o nome de complexo agroindustrial ${ }^{6}$, cuja formação, no Brasil, se deu sob os moldes da denominada modernização conservadora ${ }^{7}$, que combinada com a revolução verde ${ }^{8}$, trouxe um pacote tecnológico regado de altas doses de veneno para o campo e a mesa do brasileiro.

Esse processo ocorreu durante a vigência da ditadura militar no Brasil e, veremos que é difícil definir se todas essas modificações no campo foram resultantes dos fenômenos mundiais, se advieram da postura do Governo da época ou se todos os contextos se entrelaçam em prol do acordo entre as elites dos Estados nacionais cuja estratégia foi diminuir as proteções locais em prol do governo mundial: o capital ${ }^{9}$

\subsection{As escolhas do Regime Militar (1964 a 1985) que resultaram em quase $3.000 \%$ no Brasil de aumento do uso de agrotóxicos no Brasil.}

O aumento do consumo dos agrotóxicos no Brasil durante o regime militar foi amplamente conduzido pelas ações Estatais, verificáveis pela: a) a formação do complexo agroindustrial com a modificação da base de produção (modernização conservadora); b) o Plano Nacional de Defensivos Agrícola com a substituição da política de importação de venenos agrícolas. Ambas diretrizes políticas converteram o Brasil numa região de interesse para as empresas líderes em produção de veneno, despontando no cenário mundial.

Acrescenta-se, ainda, a criação do Sistema Nacional de Crédito Rural e uma regulamentação defasada e pouco rigorosa, baseada nas normas de defesa sanitária vegetal de 1.934 (PELAEZ et al, 2010, p. 28), as quais, além de incentivar o uso massivo de venenos, não apresentava a correspondente proteção legislativa contra os efeitos futuros gerados pelas substâncias empregadas no campo, conforme se descreverá adiante.

\footnotetext{
6. Complexo agroindustrial, sob os aspectos formais é: "o conjunto formado pela sucessão de atividades vinculadas à produção e transformação de produtos agropecuários e florestais. Atividades tais como: a geração desses produtos, seu beneficiamento/transformação e a produção de bens de capital e de insumos industriais para as atividades agrícolas; ainda: a coleta, a armazenagem, o transporte, a distribuição dos produtos industriais e agrícolas; e ainda mais: o financiamento, a pesquisa e a tecnologia, e a assistência técnica. (MÜLLER, 1989, p. 45)

7. O conceito de modernização conservadora adaptado à realidade brasileira foi inicialmente estabelecido por Alberto Passos Guimarães: "[..] Diferentemente da reforma agrária [a modernização conservadora] tem por objetivo o crescimento da produção agropecuária mediante renovação tecnológica, sem que seja tocada ou grandemente alterada a estrutura agrária” (GUIMARÃES, 1977, p. 3 apud PIRES e RAMOS, 2009, p. 416)

8. "Este modelo orientou a implantação das monoculturas, da mecanização e da aplicação de grandes quantidades de insumos agrícolas, nem sempre havendo preocupação com as variáveis sociais e ambientais" (CABRAL; IPEA, 2014, prefácio g.n).

9 . Esse acordo entre as burguesias nacionais foi o instrumento utilizado para o que François Chesnais denominou de mundialização do capital e Ariovaldo Umbelino de mundialização da agricultura.
} 


\section{O PARADIGMA DA INTENSA UTILIZAÇÃO DE AGROTÓXICOS NO BRASIL SOB O CONTEXTO DA MUNDIALIZAÇÃO DA AGRICULTURA}

2.1.1. Formação do complexo agroindustrial/modernização conservadora: instalação do paradigma da intensa utilização de agrotóxicos no país

Historicamente, o primeiro vestígio de investimento na indústria brasileira ocorreu na década de 50 (criação do plano de metas ${ }^{10}$ ), contudo, foi a partir da década de 60 e de modo mais expressivo durante o regime militar (1964 a 1985), notadamente através do II Plano Nacional de Desenvolvimento (PND), é que tivemos o auge da tentativa de abandono da vocação agrícola por meio de massivo incentivo à modernização tecnológica brasileira. (SUZIGAN, 1988)

Convém ponderar que o dilema entre a vocação agrícola e industrialização nacional acompanha a história do Brasil. O que implica dizer que, entra governo e sai governo, a pauta nacional varia, basicamente, entre a dicotomia das decisões que incrementam a produção agrícola ou consolidam a indústria nacional. Resta perguntar se somos um país com proeminência agrícola ou industrial?

Essa alternância de pautas (vocação agrícola $\mathrm{x}$ industrialização) pode ser visualizada durante boa parte dos períodos econômicos nacionais, de forma que, quando o Brasil está em uma fase de abundância de liquidez internacional, há um abandono da política de exportações (especialmente agroexportações) com medidas econômicas de fechamento do mercado nacional (diminuição da abertura comercial para o mercado externo), que, por diversos fatores, resulta em novo endividamento externo, crise de liquidez internacional e retomamos a política de exportação, resultando em um círculo histórico-vicioso, conforme segue:

\footnotetext{
${ }^{10}$. O plano de metas instrumentalizava os objetivos de crescimento a serem alcançados em diversos setores da economia nacional do governo de JK. Seu slogan era 50 anos em 05. Seu plano desenvolvimentista foi efetuado às custas de vultoso endividamento externo. Para saber mais: http://cpdoc.fgv.br/producao/dossies/JK/artigos/Economia/PlanodeMetas
} 

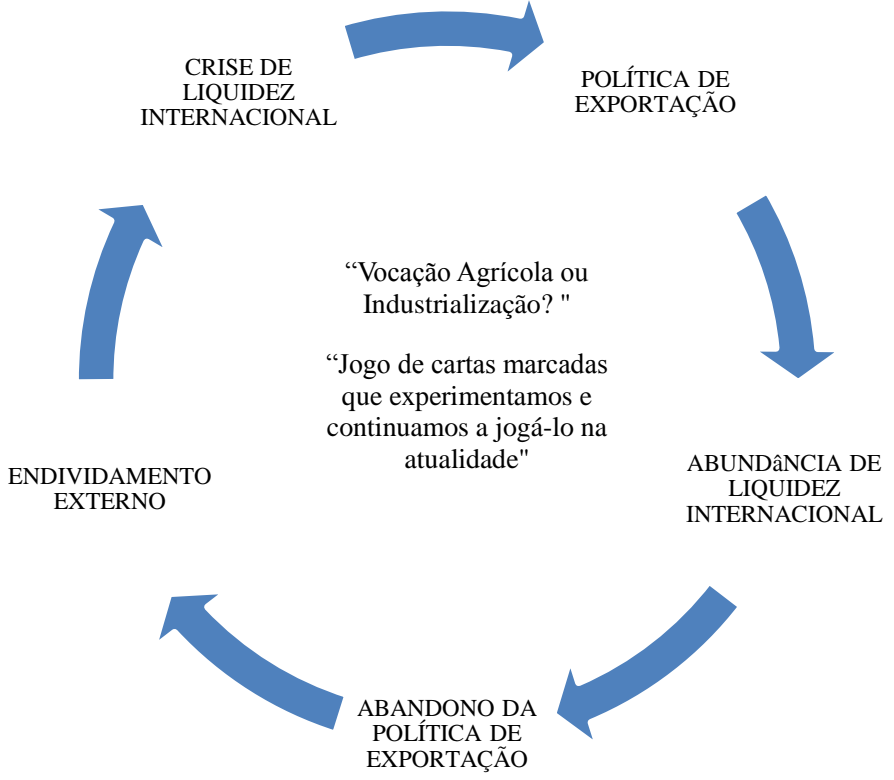

Fonte: DELGADO, 2012, p. 79/ fluxograma com adaptações da autora

Nesse sentido, foi com a pauta desenvolvimentista do regime militar que houve a formação do complexo industrial ou industrialização da agricultura ${ }^{11}$ ocorrida, portanto, entre a década de 60 e 80. O apoderamento da agricultura pelo capital se inicia pelas vias de circulação (em razão da acumulação de capital, o comércio e comunicações aumentam a dependência da agricultura) e na sequência revoluciona o seu modo de produzir, "suprimindo o divórcio entre a agricultura e a indústria” (KAUSTSKY (1980) apud MÜLLER, 1989, p. 27).

Assim, quando há a transição do modo tradicional de produzir para o moderno, ocorre a formação do complexo agroindustrial, marcado pela simbiose entre a indústria e agricultura, havendo subordinação total do trabalho agrícola ao capital industrial e financeiro (MÜLLER, 1989, p. 47).

A captura da agricultura pelo capital, instrumentalizada pelo complexo agroindustrial, que a transformou em uma indústria ao céu aberto sem a modificação na estrutura agrária nacional é denominada de modernização conservadora. A própria expressão modernização conservadora nasceu para analisar as revoluções burguesas que ocorreram na Alemanha e Japão quando da passagem de suas economias para capitalistas e industriais. Assim, as revoluções burguesas clássicas (Inglaterra, França e EUA) foram marcadas pelo rompimento total entre a burguesia e a classe que dominava anteriormente, ao contrário das

${ }^{11}$. Expressão cunhada por José Graziano da Silva (1987) 
revoluções burguesas do Japão e Alemanha que fizeram uma revolução parcial, ou seja, que se instalaram no poder, mas não destruíram totalmente a estrutura do antigo regime. (MOORE JUNIOR, 1975)

A diferença entre a modernização conservadora japonesa, alemã e brasileira foi que a elite dominante não teve a preocupação de inserir as classes inferiores no debate, ou seja, não se preocupou em expandir a cidadania para grandes parcelas da sociedade. Assim, a revolução burguesa brasileira, assim como a japonesa e alemã, não teve forças para romper totalmente com o antigo regime e instalar um capitalismo democrático (até porque a modernização do Brasil ocorreu sob a égide do regime militar), como o que ocorreu nos EUA e França. (PIRES e RAMOS, 2009, p. 421)

Um dos principais efeitos perversos advindos da modernização conservadora foi a explosão do uso de agrotóxicos no Brasil que, após a substituição das importações de fertilizantes (leia-se agrotóxicos) pela produção nacional, foi fortemente incentivado pelo Estado que, definitivamente, instaurou um novo paradigma agrário nacional, qual seja, o uso intenso e indiscriminado de agrotóxicos.

Os novos inseticidas, resultantes da pesquisa de armas químicas para a guerra, eram biologicamente muito mais potentes que qualquer outro já utilizado pela humanidade, capazes de envenenar não só os insetos, mas tudo que estivesse ao redor, inclusive o ser humano. Os incalculáveis efeitos das novas modalidades de venenos agrícolas foram denunciados por Rachel Carson na década de 60, cujo núcleo de pesquisa foi o DDT (CARSON, 2010, p.29-30)

Esses inseticidas modernos, totalmente produzidos em laboratório e altamente letais, marcaram a revolução paradigmática iniciada na década de 60 e que ainda prevalece atualmente no Brasil, qual seja, a produção agrícola com a predominância do uso de agrotóxicos. Nesse sentido, a mudança de paradigma ocorreu em sintonia ou resultante da transformação do modo de produção agrícola brasileiro.

A mundialmente conhecida revolução verde 12 que, diga-se, foi uma "revolução bem pouco verde" (ABRAMOVAY, 2012, p. 119), implantou seu pacote tecnológico cuja base de produção tem como pilar a utilização intensiva de agrotóxicos. Nesse sentido, os efeitos resultantes da utilização de agrotóxicos que contaminam toda a cadeia produtiva, sobressaem

\footnotetext{
12. "Este modelo orientou a implantação das monoculturas, da mecanização e da aplicação de grandes quantidades de insumos agrícolas, nem sempre havendo preocupação com as variáveis sociais e ambientais" (Cabral; IPEA, 2014, prefácio).
} 
dentre os impactos relacionados ao processo produtivo oriundo da industrialização da agricultura relacionados à saúde humana e ambiental (CARNEIRO et al, 2015, p. 109).

A junção entre o forte incentivo estatal e midiático com a promessa de praticidade, economicidade, redução de custos e riscos foram ingredientes imprescindíveis para o estarrecedor aumento do consumo dos agrotóxicos no país, como segue:

\section{FERTILIZANTES CONSUMIDOS NO BRASIL ENTRE AS DÉCADAS DE 60 A 80}

\begin{tabular}{|c|c|c|}
\hline 1960 & 1980 & Percentual de aumento \\
\hline 305 mil toneladas & $\begin{array}{c}10 \text { milhões de } \\
\text { toneladas }\end{array}$ & $\mathbf{2 . 8 5 7 , \mathbf { 1 4 \% }}$ \\
\hline
\end{tabular}

Com quase $3.000 \%$ de aumento do consumo de agrotóxicos altamente nocivos, o regime militar, sem dúvidas, tocou a modernização agrícola (PALMEIRA, 1989, p.93) e instaurou um novo paradigma agrário no país, qual seja o da cultura do veneno.

\subsubsection{O Plano Nacional de Defensivos Agrícolas $^{13}$ e a substituição da política de importação} de venenos agrícolas, atraindo as empresas líderes do mercado mundial para instalação no Brasil.

O principal instrumento de efetivação das políticas públicas no Brasil é o planejamento governamental ${ }^{14}$. É por meio desse documento que se organiza as ações nacionais. Especialmente no que toca à destinação de verbas públicas. Em outras palavras, esse documento expressa todos os caminhos que serão trilhados pelo Poder Público na distribuição e aplicação dos recursos públicos.

Foi durante o regime militar que se criou o primeiro planejamento econômico do país, ora denominado I Plano Nacional de Desenvolvimento (I PND: 1972-1974), instituído por meio da Lei 5.727 de 04 de novembro de 1971. Entretanto, apenas com o II PNUD que o Governo retomou a retórica de vocação agrícola nacional e com o Plano Nacional de Defensivos agrícolas que institui a política oficial de incentivo ao consumo de agrotóxicos no país.

13. Criado pela Exposição de motivos n. 17/75 do Conselho De Desenvolvimento Industrial, ligado ao Ministério da Fazenda.

${ }^{14}$. O conceito de planejamento é bastante intuitivo: "O planejamento pode ser entendido como o exercício de escolha consciente de ações que aumentem as chances de obter um resultado específico. É uma atividade dinâmica que se opõe ao improviso total, buscando orientar as decisões a partir das informações disponíveis". Esse conceito é do próprio Ministério do Planejamento. Disponível em: http://www.planejamento.gov.br. 


\title{
O PARADIGMA DA INTENSA UTILIZAÇÃO DE AGROTÓXICOS NO BRASIL SOB O CONTEXTO DA MUNDIALIZAÇÃO DA AGRICULTURA
}

O Plano Nacional de Defensivos Agrícolas foi criado em 1.975 com o intuito de substituir a política de importação de agrotóxicos, à época denominados de defensivos, instalando indústrias químicas no âmbito nacional para esse fim. Essa internalização da produção de defensivos agrícolas foi feita mediante incentivos fiscais aprovados pelo Conselho de Desenvolvimento Industrial (CDI).

O Decreto $\mathrm{n}^{\circ} 77.065 / 76$, instrumentalizou parte do II PND, de modo que previa isenção do Importo de Importação quase total para a produção de agrotóxicos no Brasil, senão vejamos:

\begin{abstract}
Art. $1^{\circ} \mathrm{O}$ Conselho de Desenvolvimento Industrial, mediante homologação de seu Presidente, o Conselho de Política Aduaneira, a Superintendência do Desenvolvimento da Amazônia, a Superintendência do Desenvolvimento do Nordeste, a Superintendência do Desenvolvimento da Pesca, e o Grupo Executivo da Indústria de Mineração poderão conceder incentivos fiscais nos termos e condições fixados pelo presente Regulamento.
\end{abstract}

[...]

II - redução de $80 \%$ (oitenta por cento) dos impostos de importação e sobre produtos industrializados para os bens referidos no inciso $I$, quando destinados a empreendimentos enquadrados nos seguintes setores:

$[\ldots]$

j) produção de fertilizantes e defensivos agrícolas e de suas matérias-primas; [...]

Convém ressaltar que esse é apenas um dos exemplos de incentivo estatal no caso dos agrotóxicos. Situação que se estende até os dias atuais, como por exemplo, o convênio 100/97 (Ministério da Fazenda) que reduz a alíquota de ICMS em 60\% para os agrotóxicos.

Importante mencionar que outra forma de se instrumentalizar o Planejamento econômico governamental destinado à agricultura é o crédito rural, que de modo singelo efetiva os objetivos traçados. O Sistema Nacional de Crédito rural também foi criado durante o regime militar por meio da Lei no 4829 de 1965, regulamentada pelo Decreto 167 de 1967. De modo singelo, o crédito rural é a principal alavanca da industrialização no campo, um dos instrumentos de consecução do planejamento governamental para a agricultura (MÜLLER, 1989, p.63).

2.1.3. Paradoxo entre o fomento estatal para as indústrias de agrotóxicos e a fragilidade do controle e monitoramento desses venenos pelo regime militar.

Ao passo que o Estado promovia uma política abrupta de implantação de nova tecnologia, bem como de transformação do modo de produção nacional que antes se valia, 
primordialmente, de defensivos agrícolas de menor potencial químico, não implementou políticas regulatórias condizentes com a nocividade dessa transformação.

O Decreto $\mathrm{n}^{\mathrm{o}} 24.114$ de 12 de abril de 1934, ainda vigente, foi o único expediente normativo que regulou o uso e consumo de agrotóxicos no país até o ano de 1989, quando ocorreu a promulgação da lei atualmente vigente: 7.802/89.

Analisando o Decreto $n^{\circ} 24.114 / 34$, podemos verificar vários pontos que nos leva a conclusão da permissividade de seu texto. Assim, vejamos os principais pontos em comparação com a Lei 7.802/89 para que tenhamos referência.

\begin{tabular}{|c|c|}
\hline \multicolumn{2}{|c|}{ COMPARATIVO DOS PRINCIPAIS ASPECTOS DO DECRETO 24.114/34 X LEI 7.802/89 } \\
\hline DECRETO 24.114/34 & LEI 7.802/89 e Decreto 4074/2002 \\
\hline \multicolumn{2}{|c|}{ SISTEMA DE REGISTRO DOS AGROTÓXICOS } \\
\hline \multicolumn{2}{|c|}{ Órgãos responsáveis pelo registro } \\
\hline $\begin{array}{l}\text { Registro efetuado apenas no Ministério da Agricultura, } \\
\text { mais especificamente na Secretária de Defesa Sanitária } \\
\text { Vegetal (SDSV), vistos os requisitos do Departamento } \\
\text { Nacional de Saúde Pública. }\end{array}$ & $\begin{array}{l}\text { Registro efetuado nos Ministérios da Agricultura, Meio Ambiente } \\
\text { e Saúde. Qualquer um destes pode indeferir o registro. }\end{array}$ \\
\hline \multicolumn{2}{|c|}{ Requisições para a concessão do registro } \\
\hline $\begin{array}{l}\text { Amostras dos produtos; certidão de análise química } \\
\text { realizada no Instituto de Química Agrícola ou outra } \\
\text { repartição oficial indicada pelo SDSV; instruções para } \\
\text { uso; indicação da sede da fábrica ou estabelecimento de } \\
\text { comércio; marca comercial e outros esclarecimentos } \\
\text { necessários. O registro é concedido após verificar-se a } \\
\text { pureza, inocuidade e a praticabilidade dos agrotóxicos }\end{array}$ & $\begin{array}{l}\text { Determina a realização de testes no campo da agronomia, } \\
\text { toxicologia, resíduos, química e meio ambiente. Cria o registro } \\
\text { temporário para pesquisa e experimentação. Obriga o registro } \\
\text { para produtos destinados à exportação. O registro é concedido } \\
\text { apenas para produtos que não tenham toxicidade superior ao de } \\
\text { outro produto para a mesma indicação já registrado. Entidades } \\
\text { públicas e privadas, além daquelas destinadas à assistência } \\
\text { técnica e pesquisa podem fornecer os laudos dos testes exigidos } \\
\text { para a concessão do registro. }\end{array}$ \\
\hline \multicolumn{2}{|r|}{ Impugnação do registro } \\
\hline $\begin{array}{l}\text { Somente a SDSV e o Departamento Nacional de } \\
\text { Produção Vegetal podem pedir a impugnação do registro } \\
\text { de um agrotóxico. }\end{array}$ & $\begin{array}{l}\text { Entidades de classe representativas de profissões ligadas ao setor } \\
\text { dos agrotóxicos, partidos políticos com representação no } \\
\text { Congresso Nacional, e entidades legalmente constituídas para a } \\
\text { defesa dos interesses difusos relacionados à proteção do } \\
\text { consumidor, do meio ambiente e dos recursos naturais podem } \\
\text { solicitar a impugnação do registro dos agrotóxicos. }\end{array}$ \\
\hline \multicolumn{2}{|c|}{ Indeferimento do registro } \\
\hline Não prevê imediato indeferimento do registro. & $\begin{array}{l}\text { Prevê imediato indeferimento do registro para agrotóxicos que o } \\
\text { Brasil não disponha de métodos de desativação, antídotos ou } \\
\text { tratamento eficaz; que revelem ser tóxicos contra o ser humano, } \\
\text { provocando distúrbios; e que se revelem mais perigosos ao } \\
\text { homem do que acusam os testes laboratoriais. }\end{array}$ \\
\hline \multicolumn{2}{|c|}{ Exigências para rotulagem } \\
\hline $\begin{array}{l}\text { Determina que o rótulo dos produtos deve conter apenas: } \\
\text { nome e marca comercial; declaração dos princípios } \\
\text { ativos e respectivas porcentagens; peso bruto e líquido; } \\
\text { doses e indicações de uso; firma e sede dos importadores } \\
\text { e dos fabricantes; declaração do registro junto ao SDSV; } \\
\text { e emblema exigido pelo Departamento Nacional de } \\
\text { Saúde Pública para as substâncias tóxicas. }\end{array}$ & $\begin{array}{l}\text { Determina que o rótulo deve conter: I) indicações para a } \\
\text { identificação do produto; II) indicações para a utilização; III) } \\
\text { informações relativas aos perigos potenciais IV) recomendação } \\
\text { para que o usuário leia o rótulo antes de utilizar o produto. }\end{array}$ \\
\hline Competências para a determinaçấ & ão das avaliações necessárias à concessão do registro \\
\hline
\end{tabular}




\begin{tabular}{|c|c|}
\hline $\begin{array}{l}\text { Os limites de resíduos são determinados apenas pelo } \\
\text { Instituto de Química Agrícola. }\end{array}$ & $\begin{array}{l}\text { Limites determinados pelos órgãos competentes de cada } \\
\text { Ministério, ANVISA (Saúde); IBAMA (Meio Ambiente); } \\
\text { Secretária de Defesa Agropecuária (Agricultura). Também } \\
\text { harmoniza com as determinações de organizações internacionais } \\
\text { responsáveis pela saúde, alimentação ou meio ambiente das quais } \\
\text { o Brasil seja membro integrante ou signatário. }\end{array}$ \\
\hline \multicolumn{2}{|c|}{ Classificação toxicológica } \\
\hline Não prevê classificação toxicológica dos agrotóxicos. & $\begin{array}{l}\text { Prevê classificação toxicológica, a cargo do Ministério da Saúde } \\
\text { regulamentar os critérios para tal classificação. }\end{array}$ \\
\hline \multicolumn{2}{|c|}{ EXIGÊNCIAS PARA AS EMBALAGENS DE AGROTÓXICOS } \\
\hline Nada dispõe sobre as embalagens dos agrotóxicos. & Nada dispõe sobre as embalagens dos agrotóxicos. \\
\hline \multicolumn{2}{|c|}{ COMPETÊNCIAS SOBRE A REGULAMENTAÇÃO DOS AGROTÓXICOS } \\
\hline $\begin{array}{l}\text { Centralidade nas mãos da União do processo de registro, } \\
\text { somente no SDSV. Aos estados e municípios cabe } \\
\text { fiscalizar o comércio dos agrotóxicos. }\end{array}$ & $\begin{array}{l}\text { Centralidade nas mãos da União do processo de registro, todavia } \\
\text { tripartite: Ministérios da Saúde, Meio Ambiente e Agricultura; } \\
\text { Estados podem legislar sobre o uso, a produção, o consumo, o } \\
\text { comércio e o armazenamento dos agrotóxicos, bem como } \\
\text { fiscalizar o uso, o consumo, o comércio, o armazenamento e o } \\
\text { transporte interno. Aos municípios cabe legislar supletivamente } \\
\text { sobre o uso e o armazenamento dos agrotóxicos. }\end{array}$ \\
\hline \multicolumn{2}{|c|}{ Receituário Agronômico } \\
\hline Não exige o receituário agronômico. & $\begin{array}{l}\text { Qualquer venda de agrotóxico deve ser feito por intermédio do } \\
\text { receituário agronômico. O profissional que disponibilizou a } \\
\text { receita pode ser punido caso ocorra algum acidente do qual seja } \\
\text { considerado culpado. }\end{array}$ \\
\hline \multicolumn{2}{|c|}{ REGULAMENTAÇÃO DA PROPAGANDA COMERCIAL DOS AGROTÓXICOS } \\
\hline Não dispõe sobre propagandas comerciais de agrotóxicos & $\begin{array}{l}\text { Cria limites e determinações para a propaganda comercial dos } \\
\text { agrotóxicos. }\end{array}$ \\
\hline \multicolumn{2}{|c|}{ MULTAS E PENALIDADES } \\
\hline $\begin{array}{l}\text { As multas e as penalidades criminais por irregularidades } \\
\text { com agrotóxicos são desatualizadas. }\end{array}$ & $\begin{array}{l}\text { Multas atualizadas e cotadas em Maior Valor de Referência para } \\
\text { estarem sempre atualizadas. Penalidades criminais por } \\
\text { irregularidades com agrotóxicos foram modernizadas. }\end{array}$ \\
\hline
\end{tabular}

Fonte: TERRA, 2008, p. 154, com adaptações da autora.

Em todos os itens acima demonstrados, vemos com clareza que a regulamentação da entrada de substâncias venenosas no Brasil foi profundamente incentivada, mas não houve implementação de medidas regulatórias suficientes.

A facilidade da entrada de agrotóxico, de modo legal, no país é demonstrada pelas poucas exigências normativas, de inserção desses produtos, a começar pela avaliação que era feita apenas pelo Ministério da Agricultura e sem a necessidade de se fazer classificação toxicológica do produto. Em termos práticos, considerando que o produto era extremamente tóxico, o silêncio estatal possibilitava a sua utilização em iguais condições com aqueles que continham menor risco à saúde do ser humano.

Com efeito, o regime militar também não havia exigia receituário agronômico, o que implica dizer que qualquer pessoa poderia comprar ou vender veneno agrícola e utilizá-lo sem orientação técnica. 
Observa-se que a entrada de agrotóxicos patenteados por indústrias estrangeiras no Brasil foi facilitada e incentivada, ao passo que a capacitação, orientação e controle do uso desses produtos altamente tóxicos foi praticamente ignorada. Como prova disso, sequer houve regulamentação específica desses produtos, visto que por 55 anos a única norma que tratava indiretamente de defensivos químicos um Decreto da vigilância sanitária editado em 1.934, como analisamos.

As facilidades de aquisição, falta de controle e fiscalização, incentivo direto do Governo para a utilização de agrotóxicos, aliados ao milagre da substituição de dezenas de homens na lida do campo por um litro de produto, fez com que o Brasil se tornasse o maior consumidor de agrotóxicos do mundo, elegendo a agricultura como "a principal fonte difusa de poluição no planeta, afetando desde a camada de ozônio até os pinguins na Antártida, passando pelo próprio homem”. (KHATOUNIAN, 2001, p.22-23)

\section{A INDÚSTRIA DE AGROTÓXICOS NO CONTEXTO DA MUNDIALIZAÇÃO DA AGRICULTURA: A ALTA CONCENTRAÇÃO DE MERCADO}

O termo mundialização do capital foi cunhado por François Chesnais em seu livro La mondialisation du capital. Segundo ele, no final do século XX houve um novo pacto de poder envolvendo a burguesia do mundo inteiro, no intuito de atender os interesses comuns dos burgueses locais. De modo que, a aliança traduziu a cooperação mútua para a retirada de barreiras nacionais que impediam a consecução dos interesses econômicos comuns dos acordantes. Essa transação "amalgamou" o capital de diferentes países em uma escala mundial. (OLIVEIRA, 2015, p.235)

Estava instalada a denominada globalização ${ }^{15}$ e palavras como soberania nacional, protecionismo econômico, intervenção do Estado na Economia, regulação de mercado, fortalecimento do Estado, passaram a ser censuradas e aliadas à noção de atraso. Agora, os termos adequados eram e ainda são: livre comércio mundial, autorregulação de mercado, privatização de empresas estatais, terceirização de serviços públicos, abertura da economia nacional para as multinacionais e tantos outros vocábulos midiáticos oriundos do neoliberalismo.

\footnotetext{
15. "O uso intenso dos termos global e globalização, vieram da mídia econômica norte-americana para a ciência e não ao contrário. Ou seja, a mídia passava a pautar a ciência e não a ciência pautar a mídia" (OLIVEIRA, 2012, p. 2)
} 


\section{O PARADIGMA DA INTENSA UTILIZAÇÃO DE AGROTÓXICOS NO BRASIL SOB O CONTEXTO DA MUNDIALIZAÇÃO DA AGRICULTURA}

A agricultura capitalista, inevitavelmente, foi absorvida por essa transformação, passando a se estruturar em três pilares: a produção de commodities, as bolsas de mercadorias e de futuro e a formação de empresas monopolistas mundiais. A atuação da agricultura neoliberal ocorre através do controle da propriedade privada da terra, do processo produtivo e industrial do campo (territorialização dos monopólios) e por meio das empresas que processam e vendem alimentos sem produzir nada no campo, subordinando os fazendeiros e camponeses à sua lógica de mercado (monopolização dos territórios) (OLIVEIRA, 2012; OLIVEIRA, 2015)

O histórico da instalação do paradigma da intensa utilização de venenos agrícolas no Brasil e consequentemente da implantação do monopólio das indústrias de agrotóxicos no cenário nacional representa, com clareza vários aspectos da transformação da agricultura capitalista, que implantou um império monopolista da indústria de alimentos, cujo intuito não é saciar a fome, mas abastecer a ganância econômica da modernidade, qual seja, o domínio e controle universal dos alimentos e insumos químicos que se tornaram imprescindíveis para o campo moderno.

Trata-se de um impiedoso controle da indústria de alimentos e, portanto da vida dos seres humanos por algumas empresas, já que "entre os 24 maiores vendedores de agrotóxicos no mundo, 15 também mantém atividades na indústria de sementes e 9 na indústria farmacêutica" (BULL E HATHAWAY, 1986, p.151). Logo, quem envenena e adoece o ser humano também produz e comercializa o remédio, constituindo um enredo fático que, infelizmente, compatibiliza-se com as típicas teorias da conspiração.

O mercado de venenos químicos agrícolas já nasceu dominado por grandes empresas ${ }^{16}$ que se engendraram rapidamente nesse novo e bilionário nicho de mercado ${ }^{17}$. O gráfico a seguir demonstra que oito empresas sempre dominaram mais de $60 \%$ de todo o mercado mundial de produção e comércio de venenos agrícolas.

\footnotetext{
16. O primeiro agrotóxico que foi comercializado no mundo foi o DDT, patenteado pela Monsanto que ainda é uma das 06 maiores empresas do mundo no ramo. Fonte: http://contraosagrotoxicos.org/os-12-produtos-maisperigosos-criados-pela-monsanto/+\&cd=1\&hl=pt-BR\&ct=clnk\&gl=br\&client=firefox-b. Acesso em: 14/01/18.

17. Durante o regime militar, o Estado, através da política de substituição das importações, tentou nacionalizar a produção de agrotóxicos, mas por uma série de fatores, a indústria nacional foi praticamente absorvida pelas multinacionais. "As vendas de agrotóxicos não passam de 7\% do valor de todas as vendas das indústrias químicas instaladas no País, e nem chegam a metade de $1 \%$ do produto da indústria brasileira como um todo" (BULL E HATHAWAY, 1986, p. 149)
} 


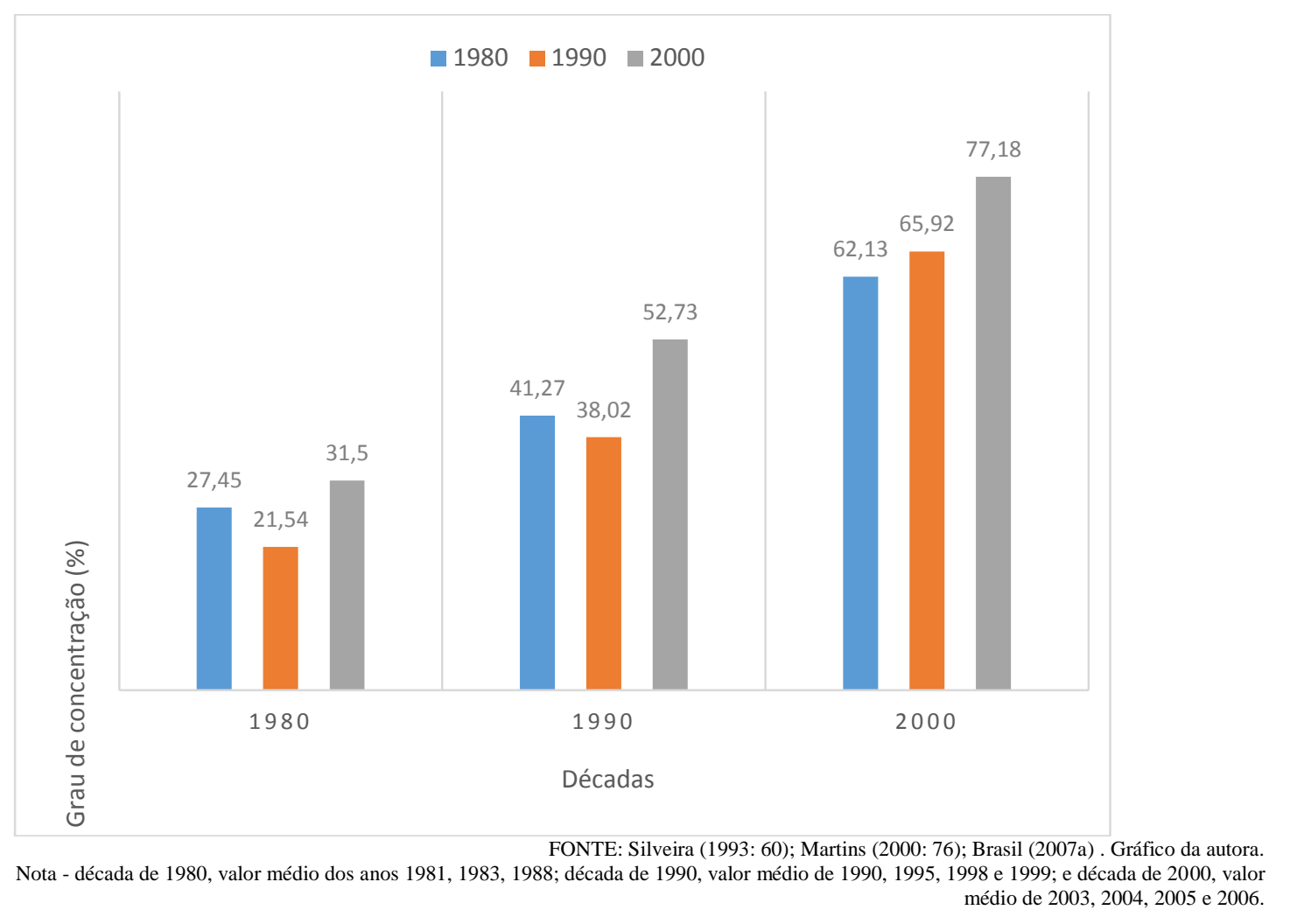

A análise de dados da década seguinte demonstra que o contexto monopolizado do mercado mundial tende a estar cada vez mais concentrado e oligopolizado, visto que, nos anos de 2009 e 2010, 67\% do mercado mundial está dominado por seis empresas e não oito, como nos anos de 2.000. Um dos principais instrumentos utilizados pelas grandes empresas que atuam no ramo de venenos agrícolas é a aquisição, do todo ou em parte, de empresa concorrente. Na década de 90 aos anos 2.000, várias foram as fusões e aquisições de empresas, fazendo com que, cada vez mais poder fique concentrado em um menor número de pessoas, como segue. 


\section{O PARADIGMA DA INTENSA UTILIZAÇÃO DE AGROTÓXICOS NO BRASIL SOB O CONTEXTO DA MUNDIALIZAÇÃO DA AGRICULTURA}

\begin{tabular}{|c|c|c|c|c|c|}
\hline \multicolumn{6}{|c|}{ Principais fusões e aquisições entre as empresas produtoras de agrotóxicos 1990-2000 } \\
\hline ANO & $\begin{array}{l}\text { TIPO } \\
\text { DE } \\
\text { TRANSAÇÃO }\end{array}$ & $\begin{array}{l}\text { EMPRESAS } \\
\text { ADQUIRIDAS }\end{array}$ & $\begin{array}{l}\text { EMPRESAS } \\
\text { ADQUIRENTES } \\
\text { /RESULTANTES }\end{array}$ & $\begin{array}{l}\text { VALOR DAS } \\
\text { TRANSAÇÕES } \\
\text { (US\$ bilhões) }\end{array}$ & RESULTADOS \\
\hline 1994 & Aquisição & Cyanamid & $\begin{array}{l}\text { America } \\
\text { Home Products }\end{array}$ & 9,7 & $\begin{array}{ll}\text { Aumento } & \text { da } \\
\text { participação } & \text { no } \\
\text { mercado } & \\
\end{array}$ \\
\hline 1996 & Fusão & $\begin{array}{l}\text { Ciba-Geigy e } \\
\text { Sandoz }\end{array}$ & Novartis & $\ldots$ & $\begin{array}{ll}\text { Aumento } & \text { no } \\
\text { portifólio } & \text { de } \\
\text { produtos } & \\
\end{array}$ \\
\hline 1999 & Fusão & $\begin{array}{l}\text { Hoechst e } \\
\text { Rhone-Poulenc }\end{array}$ & Aventis & 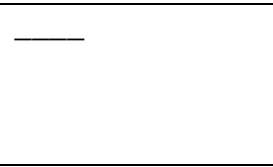 & $\begin{array}{lr}\text { Liderança } & \text { no } \\
\text { mercado } & \text { de } \\
\text { fármacos } & \mathrm{e} \\
\text { agrotóxicos } & \\
\end{array}$ \\
\hline 2000 & Fusão & $\begin{array}{l}\text { AstaZeneca } \\
\text { Novartis }\end{array}$ & Syngenta & & $\begin{array}{l}\text { Liderança no } \\
\text { mercado mundial } \\
\text { de agrotóxicos }\end{array}$ \\
\hline 2001 & Aquisição & $\begin{array}{l}\text { American } \\
\text { Cynamid }\end{array}$ & BASF & 3,8 & $\begin{array}{lr}\text { Aumento de } & 52 \% \\
\text { de participação no } & \text { nercado } \\
\text { mercón de } \\
\text { agrotóxicos }\end{array}$ \\
\hline 2002 & Aquisição & $\begin{array}{ll}\text { Aventis } & \text { Crop } \\
\text { Science } & \end{array}$ & Bayer & 6,6 & $\begin{array}{lr}\text { Aumento de } & 84 \% \\
\text { de participação no } & \text { no } \\
\text { mercado } & \text { de } \\
\text { agrotóxicos } & \end{array}$ \\
\hline
\end{tabular}

Valendo-se de todos os instrumentos possíveis para avançar e concentrar cada vez mais capital, a indústria dos agrotóxicos, de 2000 a 2012, aumentou seu faturamento em 284\%, lucrando R 33 bilhões em 2016, ao passo que o total de gastos diretos do Ministério da Agricultura inteiro foi de R \$ 13,5 bilhões e da Anvisa, R \$ 682 milhões ${ }^{18}$

A insustentabilidade ${ }^{19}$ da agricultura capitalista instalada a partir do atendimento dos interesses das burguesias nacionais, baseia-se no que o professor Wanderley Pignati denomina de "processo químico dependente", onde o produtor depende da semente transgênica ou híbrida, que por sua vez depende de agrotóxicos ou fertilizantes para ser cultivada. E nesse processo de dependência, nós brasileiros somos reféns da autonomia e independência das indústrias agroquímicas, que cada vez mais ditam as regras da produção agrícola mundial.

18. Dados oriundos do Sindag e PLOA 2016 (Projeto de Lei orçamentária Anual): Disponível na página eletrônica do Ministério do Planejamento.

19. Trata-se de um processo de insustentabilidade ambiental: na primeira etapa se desmata/destrói o cerrado e/ou a floresta; numa segunda fase se implanta um sistema agropecuário dependente de alta tecnologia, de equipamentos e de sementes híbridas ou transgênicas dependentes de agrotóxicos e fertilizantes químicos para se desenvolverem; como consequência, a terceira etapa deste processo provoca danos imediatos (agudos) e/ ou tardios (crônicos) à saúde humana e ambiental ou cria situações de riscos para além dos locais das plantações agrícolas, ampliando os agravos, com impacto negativo social, sanitário e ambiental.(PIGNATI, et al, 2006) 


\section{CONCLUSÃO}

O país que está entre os dez mais desiguais do mundo, é uma das dez maiores economias do planeta e também é um dos maiores produtores de alimentos do globo ${ }^{20}$. Os paradoxos nacionais são demonstrados pelos próprios destaques mundiais que o Brasil detém. E a relação dos problemas sociais do Brasil com a questão agrária é, por mais que alguns queiram fazer crer, inegável.

Estudiosos se contorcem em argumentos e análises que visam entender os problemas sociais da nação, mas se recusam a aceitar que o cerne das mazelas brasileiras é fundiário, pois que "a questão agrária engole a todos e a tudo". O Brasil é agrário, e o atraso intencional oligárquico é um poderoso instrumento utilizado pelas classes dominantes na manutenção de seus arbítrios. (MARTINS, 1994)

A história do Brasil é pautada por acordos entre as elites nacionais, que, oportunamente, se unem e se transformam ${ }^{21}$ visando a sua manutenção no poder. Os instrumentos mudam, mas o intuito é o mesmo, o lucro por meio da exploração do trabalho alheio. A mundialização da agricultura foi uma estratégia diferente, mas com o mesmo intuito, ou seja, as burguesias nacionais se uniram e firmaram acordos que transcenderam os limites de seus países.

O interesse das burguesias ainda era o mesmo, qual seja, obtenção de mais e mais capital e a agricultura ainda era um entrave para o capitalismo; foi necessário absorvê-la. Nesse contexto é que foi lançada a modernização da agricultura, cujo intuito era retirar a independência do setor, tornando-o totalmente dependente do sistema.

Um dos pilares para a subjugação do campo ao capital, foi a implantação da quimificação agrícola que atrelada às sementes geneticamente modificadas retiraram a independência e capacidade de autossubsistência do produtor. Àquele que antes era empecilho ao giro do capital, passou a ser cliente obrigatório da indústria química.

A junção entre o financiamento público, forte incentivo da mídia, e aparente economia de tempo e dinheiro prometidas ao produtor $^{22}$, fizeram com que as indústrias de agrotóxicos aumentassem em quase $300 \%$ o seu lucro em pouco mais de uma década ${ }^{23}$,

\footnotetext{
20. FAO: OCDE-FAO: perspectivas agrícolas 2015-2024

${ }^{21}$. A obra de Francisco de Oliveira: "a economia da dependência imperfeita" analisa o surgimento da burguesia agrária no Brasil e suas modificações ao longo dos anos.

${ }^{22}$. Falamos em falsa economia porque as externalidades do uso de agrotóxicos não são mensuradas (custos com saúde pública, custos de recuperação ambiental, etc)

${ }^{23}$. Entre os anos de 2000 e 2012. Fonte: Sindag/sindveg
} 
chegando à cifra de 33 bilhões de reais em 2016. E 67,8\% desse surreal nicho de mercado é dominado, no mundo inteiro, por apenas 06 indústrias químicas.

O lucro das empresas de agrotóxicos que atuam no mercado nacional poderia custear boa parte das pastas dos Ministérios da União. A disparidade é tão grande que a soma dos orçamentos inteiros do Ministério da Agricultura com o da Anvisa resultam em pouco mais de um terço do lucro da indústria de venenos agrícolas no Brasil.

A análise de apenas uma das facetas do agronegócio brasileiro (da indústria de agrotóxicos) nos leva a entender que o agro só é “pop, tech e tudo ${ }^{24}$ ” para poucos, já que do DDT ao Glifosato, poucos ganham e muitos perdem.

\section{REFERÊNCIAS}

ABRAMOVAY, Ricardo. Muito além da economia verde. São Paulo: Ed. Abril, 2012.

ALVES FILHO, José Prado. O uso de agrotóxicos no Brasil: controle social e interesses corporativos. São Paulo: Ed. Annablume, 2002.

BULL, DAVID E DAVID HATHAWAY. Pragas e venenos: agrotóxicos no Brasil e no Terceiro Mundo. Petrópolis, RJ: Ed. Vozes, Oxfam e fase, 1986.

CARNEIRO, Fernando Ferreira et al. (Org.). Dossiê ABRASCO: uma alerta sobre os impactos dos agrotóxicos na saúde. Rio de Janeiro: EPSJV; São Paulo: Expressão Popular, 2015.

CARSON, Rachel. Primavera silenciosa. Traduzido por Cláudia Sant'anna Martins. São Paulo: Ed. Gaia, 2010.

COUTINHO, Carlos Nelson. Balanços e Perspectivas. In: Revista Praga. Estudos Marxistas. Número 6, setembro de 1998. Editora Huicitec, São Paulo. Página 138 in ROCHA, André. Revista Campia, jan-julh 2015. A reforma do Estado de FHC: lógica neoliberal e ideologia sociodemocrata.

DELGADO, Guiherme Costa. Do capital financeiro na agricultura à economia do agronegócio: mudanças cíclicas em meio século (1965-2012). Porto Alegre: Editora da UFRGS, 2012.

FOLGADO, Cléber. Queremos ser os maiores produtores de alimentos saudáveis para a população. Rio de Janeiro: 2012. SPSJV/FIOCRUZ. Entrevista concedida a Raquel Júnia em: 03/07/2012. Disponível em: www.epsjv/fiocruz.br, acesso em: 17/08/2017.

\footnotetext{
${ }^{24}$. Essa expressão é oriunda da campanha lançada pela rede globo de televisão, onde há a afirmação de que o "agro é tech, é pop, é tudo".
} 
FUTINO, Ana Maria e José Maria F. J. da Silveira. Plano Nacional de defensivos agrícolas e a criação da indústria brasileira de defensivos. Boletim técnico do Instituto de Economia Agrícola, agricultura em São Paulo, SP, 37 (3): 129-146, 1990.

KUHN, tomas S. A estrutura das revoluções científicas. 5 Ed. São Paulo: Editora Perspectiva S.A, 1997 in Revista ensaio, Belo horizonte, v.14, n.03, p. 351-358, set-dez, 2012, por Roberta Chiesa Bartelmebs.

MACHADO, Luís Carlos Pinheiro e Luís Carlos Pinheiro Filho. A dialética da agroecologia: contribuição para um mundo sem veneno. São Paulo: Expressão popular, 2014.

MARTINS, José de Souza. O poder do atraso: ensaios de sociologia da história lenta. São Paulo: Ed. HUCITEC, 1994.

MOORE JUNIOR, Barrington. As origens sociais da ditadura e da democracia: senhores e camponeses na construção do mundo moderno. São Paulo: Martins Fontes, 1975.

MÜLLER, Geraldo. Complexo agroindustrial e modernização agrária. São Paulo: Ed. HUCITEC: EDUC, 1989.

OLIVEIRA, A. U. A mundialização do capital e a crise do neoliberalismo: o lugar mundial da agricultura brasileira. Geousp - Espaço e Tempo (Online), v. 19, n. 2, p. 229-245, ago. 2015. ISSN 2179-0892.

A. U. A mundialização da agricultura brasileira. XII Colóquio Internacional de Geocrítica. Disponível em: http://www.ub.edu/geocrit/coloquio2012. Acesso em: 14/01/18.

, A. U. A mundialização da agricultura brasileira. São Paulo, SP. Ed. Iãnde, 2016.

PALMEIRA, Moacir. Modernização, Estado e Questão Agrária. Estudos Avançados, São Paulo, v. 3, n. 7, 1989, p. 87-108.

PELAEZ, Victor et al. A regulamentação dos agrotóxicos no Brasil: entre o poder de mercado e a defesa da saúde e do meio ambiente. Paraná: Ed. UFPR. Revista de Economia, v.36, n.1 (ano 34), p. 27-48, jan./abr.2010.

A indústria de agrotóxicos: Debate sobre os impactos dos agrotóxicos e o modelo produtivo agrícola brasileiro. Curitiba, PR, 2011. Disponível em: https://contraagrotoxicosdf.files.wordpress.com/2011/06/indc3bastriaagrotoxicos31-05-11.pdf. Acesso em: 14/01/18.

Acordos de cooperação na indústria de agrotóxicos - 2000-09. Indic. Econ. FEE, Porto Alegre, v. 38, n. 2, p. 65-82, 2010. Disponível em: https://revistas.fee.tche.br/index.php/indicadores/article/download/2451/2851+\&cd=1\&hl=ptBR\&ct=clnk\&gl=br\&client=firefox-b-ab. Acesso em: 14/01/18.

PIGNATI, Wanderlei Antônio, et al. Acidente rural ampliado: o caso das "chuvas" de agrotóxicos sobre a cidade de Lucas do Rio Verde - MT. Revista de Ciência \& Saúde Coletiva, 12(1):105-114, 2007. 
PIRES, Murilo José de Souza e Pedro Ramos. O termo modernização conservadora: sua origem e utilização no Brasil. Revista Econômica do Nordeste, vol. 40, n. 03, julhosetembro, 2009.

SOARES, Wagner Lopes e Marcelo Firpo Porto. Atividade agrícola e externalidade ambiental: uma análise a partir do uso de agrotóxicos no cerrado brasileiro. Ciência e Saúde coletiva n. 12, p. 131-143, 2007. Disponível em: http://www.scielo.br/pdf/csc/v12n1/12.pdf. Acesso em: 21/08/2017.

SUZIGAN, Wilson. Estado e industrialização no Brasil. Revista de economia política, vol. 8, $\mathrm{n}^{\circ}$ 4, outubro-dezembro/1988. Disponível em: www.rep.org.br/pdf/32-1.pdf. Acesso em: $18 / 08 / 2017$.

TERRA, Fábio Henrique Bittes. A universidade de agrotóxicos no Brasil. (dissertação de mestrado UFPR) Curitiba, 2008. Disponível em: acervodigital.ufpr.br/handle/1884/15861. Acesso em: 20/08/2017. 